\title{
Technical note on measuring run-off dynamics from pavements using a new device: the weighable tipping bucket
}

\author{
T. Nehls, Y. Nam Rim, and G. Wessolek \\ Technische Universitaet Berlin, Institute of Ecology, Chair for Soil Conservation, Ernst-Reuter-Platz 1, \\ 10587 Berlin, Germany
}

Received: 22 September 2010 - Published in Hydrol. Earth Syst. Sci. Discuss.: 6 December 2010

Revised: 7 March 2011 - Accepted: 3 May 2011 - Published: 6 May 2011

\begin{abstract}
Due to climate change, cities need to adapt to changing rainfall and rainwater run-off dynamics. In order to develop an corresponding process based run-off model for pavements, we had to improve the measurement technique to detect run-off dynamics in an appropriate high resolution.

Traditional tipping buckets (TB) have a comparable low volume resolution, capable to quantify the highest intensities in a range of expected flows. This results in varying temporal resolutions for varying flow intensities, especially in low resolutions for small flow events. Therefore, their applicability for run-off measurements and other hydrological process studies is limited, especially when the dynamics of both small and big flow events shall be measured.

We improved a TB by coupling it to a balance and called it weighable tipping bucket (WTB). This paper introduces the device set up and the according data processing concept. The improved volume and temporal resolution of the WTB are demonstrated. A systematic uncertainty of TB measurements compared to WTB measurements is calculated. The impact of that increased resolution on our understanding of run-off dynamics from paved urban soils are discussed, exemplary for the run-off and the surface storage of a paved urban soil.

The study was conducted on a permeably paved lysimeter situated in Berlin, Germany. Referring to the paved surface, the TB has a resolution of $0.1 \mathrm{~mm}$, while the WTB has a resolution of $0.001 \mathrm{~mm}$. The temporal resolution of the WTB is $3 \mathrm{~s}$, the TB detects individual tippings with $0.4 \mathrm{~s}$ between them. Therefore, the data processing concept combines both the benefits of the balance to measure small intensities with that of the TB to measure high flow intensities.

During a five months period (July to November 2009) 154 rain events were detected. Accordingly, the TB and WTB detected 47 and 121 run-off events. The total run-off was
\end{abstract}

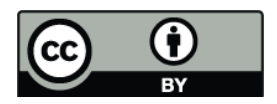

Correspondence to: T. Nehls (thomas.nehls@tu-berlin.de)
$79.6 \mathrm{~mm}$ measured by the WTB which was $11 \%$ higher than detected by the TB. $95 \%$ of that difference can be appointed to water, which evaporated from the TB. To derive a surface storage estimation, we analyzed the WTB and TB data for rain events without run-off. According to WTB data, the surface storage of the permeable pavement is $1.7 \mathrm{~mm}$, while using TB data leads to an overestimation of $47 \%$ due to low volume resolution of the TB.

Combining traditional TB with modern, fast, high resolution digital balances offers the opportunity to upgrade existing TB systems in order to improve their volume detection limit and their temporal resolution, which is of great advantage for the synchronization of water balance component measurements and the investigation of hydrological processes. Furthermore, we are able to quantify the uncertainty of flow measurements gained with traditional tipping buckets.

\section{Introduction}

The urban water balance and its dynamics is not understood completely (Ragab et al., 2003). Measuring run-off from permeable paved urban soils in a high temporal and quantitative resolution is the prerequisite for the formulation of a processbased run-off model. Such a model, based on meteorological data and pavement characteristics would be capable to predict changes in the urban run-off dynamics for changing rain sum and intensity distribution due to climate change as forecasted (Arnbjerg-Nielsen, 2006). Such models are therefore of interest for the development of climate change adaptation strategies for urban areas, such as drainage adjustment (Arnbjerg-Nielsen and Fleischer, 2009; Faram et al., 2010), use of run-off water for cooling by evapotranspiration (Gobel et al., 2007b; Nakayama and Fujita, 2010) or risk assessment for increased infiltration (Gobel et al., 2007a; Nehls et al., 2008).

Published by Copernicus Publications on behalf of the European Geosciences Union. 


\subsection{Studying run-off from paved urban soils}

In our study, the water balance of pavements is measured using $1 \mathrm{~m}^{2}$ weighable lysimeters (for details see Rim et al., 2009). On those lysimeters, small rain events lead to small absolute run-off flows. However, these have to be detected. For understanding the processes which influence run-off generation from paved soil surfaces, small rain events are of the same or even higher importance than storm events for two reasons:

(i) Figure 1 demonstrates the long term precipitation event sum distribution. It highlights the contribution of small precipitation events to the cumulative sum of precipitation. Similar, precipitation events with small intensities contribute substantially to the total sum of precipitation. At the Station Marienfelde 5\%, 50\% and $95 \%$ of the cumulative rainfall are generated by rain fall events with intensities smaller than $0.0076,0.0263$ and $0.1886 \mathrm{~mm} \mathrm{~min}^{-1}$ respectively.

(ii) The run-off (RO) is a non-linear function of precipitation sum $(P)$ and intensity (Sen and Altunkaynak, 2006). That means different run-off generation processes might be of differing effectiveness for different rainfall sums and intensities. Therefore, one needs to study run-off for small and heavy rainfall events.

The processes to study include infiltration of rain water into the soil through cracks and pavement joints, surface storage due to depletions in the relief and due to porosity of pavement materials, evaporation of rain water from the surface and run-off concentration, e.g. surface flow dynamics. The surface storage $V_{\mathrm{S}}[\mathrm{mm}]$ also named initial loss or rain loss (Hino et al., 1988; Arnbjerg-Nielsen and Harremoes, 1996) may have a great influence on run-off especially for small rain events. A certain amount of the rain water can be stored at the surface of the pavement and in the seam soil material between the pavers (Nehls et al., 2006). As water can evaporate from $V_{\mathrm{S}}$, it is important to quantify it (Mansell and Rollet, 2009). The surface storage of pave stones can be easily measured for different rain intensities in the laboratory. It should additionally be estimated for whole pavements, including the storage capacities of the surface relief and the seam soil material. It can be estimated from the mass increase of a paved weighable lysimeter during a rain event until run-off starts. However, this requires a mass detection system for the lysimeter, which has a high mass and temporal resolution. Wind, which accompanies rain events frequently can disturb such measurements.

Alternatively, the surface storage can be gained from runoff measurements for rain events with differing intensities and rain sums. Because of the great importance of small rain events and low intensity events, the measuring device must be capable to quantify run-off events with very differing intensities, each with the appropriate temporal and volume resolution. For the detection of small flow rates down to $0.007 \mathrm{~mm} \mathrm{~min}^{-1}$ a bucket on a balance with a high resolution would be capable. However, the logger system and

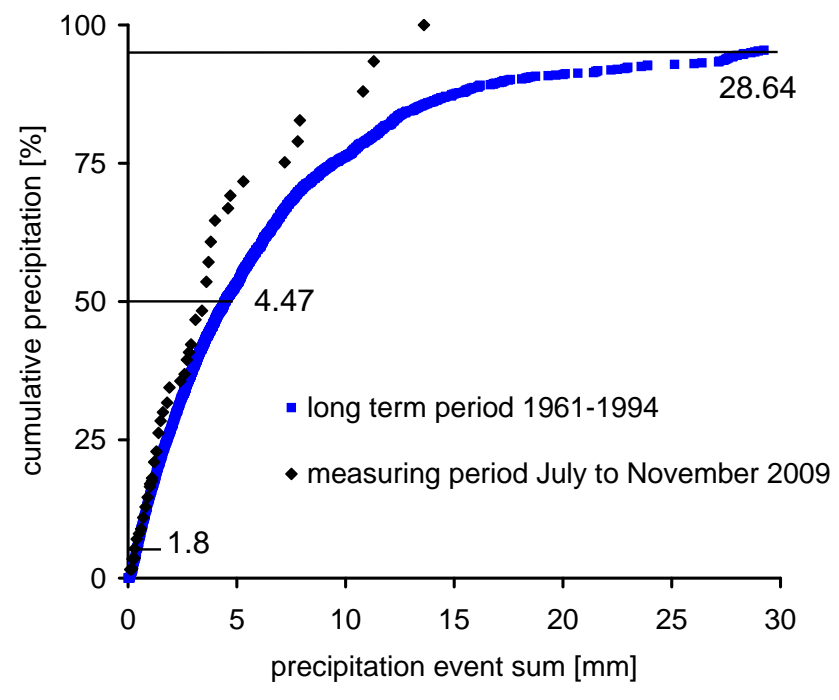

Fig. 1. Contribution of individual precipitation event sums (separated by a $10 \mathrm{~min}$ dry period) to the cumulative sum of precipitation at the station Berlin-Marienfelde, 1961-1990 (solid line, $\mathrm{N}=11363$ ) and of the rain events during the observation period of this study, 8 July to 30 November 2009 (dashed line, $N=154$ ). The $5 \%, 50 \%$ and $95 \%$ quantiles are marked for the period 1961-1990.

the balance must have a high mass and temporal resolution and good shock absorption. The higher the resolution of a balance, the smaller is its weighing range. In our case the available balance has a range of $4000 \mathrm{~g}$. An according 41 bucket would be filled after less than one average rain event, assuming a run-off coefficient of 1 and the rain distribution from Fig. 1. So the use of a bucket would lead to high maintenance efforts, while a tipping bucket is self-emptying and enables a continuously, low maintenance monitoring of runoff events. Alternative flow measurement techniques such as venturi canals, rotameters or rotary piston meters work only with completely filled tubes or filled flow cross sections of gutters thus would complicate the setup.

\subsection{Tipping buckets in hydro-meteorological instrumentation}

The functional principle of tipping buckets (TB) is to count how often the two buckets with known volume are filled and self-emptied. It is known since the 1950ies and since then often used in hydro-meteorological instrumentation such as rain-gauges (W.M.O, 1961) or stem flow meters (White and Rhodes, 1970). Tipping buckets have also been regularly employed for run-off measurements since the early 1960s (Pillbury et al., 1962; Edwards et al., 1974; Khan et al., 1997). They are also used in wick samplers and lysimeters for the measurement and sampling of seepage water and for multicompartment sampling (Meissner et al., 2010). 
TBs are robust, reasonably-priced devices for the discontinuous detection of flow events with a wide spectrum of flow intensities and a high temporal resolution for flow intensities which the bucket was dimensioned for (Habib et al., 2001). During instrumentation of our lysimeters we became aware that the traditional TB is not appropriate for a constant, high temporal and volume resolution detection of runoff with both very low and very high flow intensities. In the following it is explained why it is not suitable as it is and how we improved the system.

\subsection{Limited volume and temporal resolution of tipping buckets}

Before the first tipping and after the last tipping, the TB delivers no information about the water level in the bucket and about the current flow into or out of the bucket. Therefore, the TB is not appropriate to determine the accurate duration of flow events. There is no information on the real beginning of the flow event from the tipping signals, as the first drops of the event must not lead to a tipping signal (even if the first drop would lead to a tipping, we would not know that it was the first drop). Also, there is no information about the water left in the bucket from the previous flow event(s).

Similar, the time of the end of a flow event cannot be determined exactly, because it is not known when the flow stopped unless the last drop caused a tipping (and also then we can not know that it was the last drop).

The problem of incorrect flow event durations gets more important with decreasing flow intensities for a given bucket volume. If flow event sums are smaller than the bucket volume, individual flow events are no longer detectable.

The starting point of a flow event can be extrapolated from the behavior of the flow during the reliable TB measuring period, especially when the rise of the flow intensity at the beginning of the event is very steep. However, this is already interpretation of measured data and not measuring.

The TB are usually dimensioned to detect the highest of an expected range of flow intensities. This is done by choosing the bucket size according to the expected flow rate and the maximum possible tipping frequency. Then, TBs provide proper information especially during high flow events, after the first tipping and before the last tipping of the buckets. This duration is the "reliable TB measurement period".

Because of the distinct volume of the bucket, low flow intensities lead to low temporal resolutions, high flow intensities lead to high temporal resolutions. The problem of the resulting high measurement uncertainties are discussed by $\mathrm{Yu}$ et al. (1997). As a wide range of flow intensities must be detected and small event intensities are of the same interest as great events, TBs are inappropriate measuring devices in terms of temporal resolution.

Also, different flow events can not be detected with an adequate, a priori chosen temporal resolution. This is a disadvantage of the TBs concerning the harmonization of mea- surements of different water balance elements in the same catchment. The bucket volume could be decreased to increase the resolution for small events but that would decrease the maximum detectable flow rate of the TB. Also, the filling of the bucket needs to be sufficiently long compared to the duration of a complete tipping (Yu et al., 1997). Otherwise, the TB just runs over without quantification of the flow.

It can be argued, that the balance for the TB itself is closed over long periods. Water, which is left in the bucket after an event will add to the next event. With that argument, TBs have been employed for run-off studies aiming at the measurement of annual mean run-off amounts for paved urban soils (Wessolek and Facklam, 1997; Wessolek et al., 2008). In systems, where the tipping bucket can not be sealed against the atmosphere, as in our setup, water could be lost from the bucket due to evaporation. Even small evaporated amounts may then sum up to substantial losses at the end of the observation period.

The traditional TB had to be improved to be applicable for our studies of run-off generation and run-off dynamics from paved urban soils. The volume resolution, given by the bucket size of the TB had to be improved substantially, without decreasing the capacity to detect high flow events. By increasing the volume resolution, the temporal resolution would be increased.

\subsection{Aims of the paper}

This paper (i) introduces the weighable tipping bucket, WTB (see Sect. 2.2) and (ii) a concept how to process WTB data (see Sect. 2.3). We demonstrate, how the (iii) volume (see Sect. 3.1) and temporal resolution (see Sect. 3.3) of the traditional TB have been improved, and quantify the systematic uncertainty of the TB compared to the WTB (see Sect. 3.2).

It is then demonstrated exemplary, how the improved resolution of the WTB changes the quantification of (iv) the runoff sum for a certain period of time (see Sect. 3.4) as well as for (v) the surface storage capacity, $V_{\mathrm{S}}$ (see Sect. 3.5).

\section{Material and methods}

\subsection{Experimental site}

The study has been conducted on a permeably paved lysimeter in Berlin-Marienfelde, Germany. The mean annual temperature (1961-1990) at the station is $8.9^{\circ} \mathrm{C}$, the mean annual precipitation (1961-1990) is $536 \mathrm{~mm}$ and the mean potential evapotranspiration is $361 \mathrm{~mm}$ (Senstadt Berlin, 2001). A lysimeter with a $1 \mathrm{~m}^{2}$ surface has been permeably paved with concrete pavers (Rim et al., 2009). They are $0.4 \times 0.4 \times 0.05 \mathrm{~m}$ in size and the pavement has a seam portion of $10 \%$ which was estimated from photos of the surface using a digital image analysis method described in Rim (2008). Around the permeably sealed surface, there is 
a gutter system, which leads the run-off into the lysimeter basement, where it is detected by the TB.

During the observation period 8 July to 1 December 2009, 154 rain events (each separated by a 10 min dry period) took place. The precipitation was measured using a Hellmann rain-gauge. The corresponding run-off events were detected with the traditional TB and the new WTB system introduced in the following.

\subsection{Introduction of the weighable tipping bucket}

In the lysimeter basement, the run-off water is collected by a tipping bucket (Pulsameter MC 1, UP Umweltanalytische Produkte GmbH, Cottbus, Germany) with a bucket volume of 0.11 which equals $0.1 \mathrm{~mm}$ of run-off from the paved surface. During calibration the average of the two bucket volumes $\left(\bar{V}_{\mathrm{B}}\right)$ was measured to be 0.0981 (standard error $=0.0021$ ).

The TB has been coupled to a digital balance (Acculab VIC-4KG, Sartorius AG, Goettingen, Germany) with a resolution of $1 \mathrm{~g}$. The TB is mounted at the end of a leverage with the length $l_{1}$, which is pivoted at the other end (Fig. 2). At the distance $l_{2}=0.51 \times l_{1}$, a screw transmits the force to the digital balance. The distance $l_{2}$ was estimated during calibration of the balance system using $100 \mathrm{~g}$ standard weights. The calibration of the balance has been repeated at the end of the measuring period. The drift of the balance has been lower than $1 \mathrm{~g}$. However, we take twice the resolution of the balance as its detection limit.

The screw connects the balance to the leverage and allows to adjust the TB horizontally, which is a prerequisite for the proper working of it. Due to the leverage effect, the accuracy of the whole WTB system is $V_{\min } \approx 0.0011$.

Both the signals from the TB and the WTB are recorded by data loggers. The temporal resolution of the TB varies with the run-off intensity, the maximum flow intensity detectable by the TB is $15 \mathrm{~mm} \mathrm{~min}^{-1}$. Due to some technical reasons in our individual case the temporal resolution of the data logger connected to the balance is $3 \mathrm{~s}$.

\subsection{WTB data processing concept}

Due to the leverage effect, the detected torques processed and stored as masses by the digital balance were multiplied by 0.51 and divided by the water density of $1 \mathrm{~g} \mathrm{~cm}^{-3}$ to get the water volume in the tipping bucket. The TB signals are processed as follows: the first tipping is accounted $0.5 \bar{V}_{\mathrm{B}}$, every following tipping is accounted $\bar{V}_{\mathrm{B}}$. After the last tipping, another $0.5 \bar{V}_{\mathrm{B}}$ is added to the sum of tippings before. That evenly distributes the water left in the bucket after the last tipping of an event and the water collected before the first tipping of the subsequent event to all of the individual events.

The sum of the run-off event measured by the $\mathrm{TB}\left(\mathrm{RO}_{\mathrm{TB}}\right)$ is therefore:

$\mathrm{RO}_{\mathrm{TB}}=\frac{n \bar{V}_{\mathrm{B}}}{A} \quad(n \in \mathbb{N}) \quad[\mathrm{mm}]$
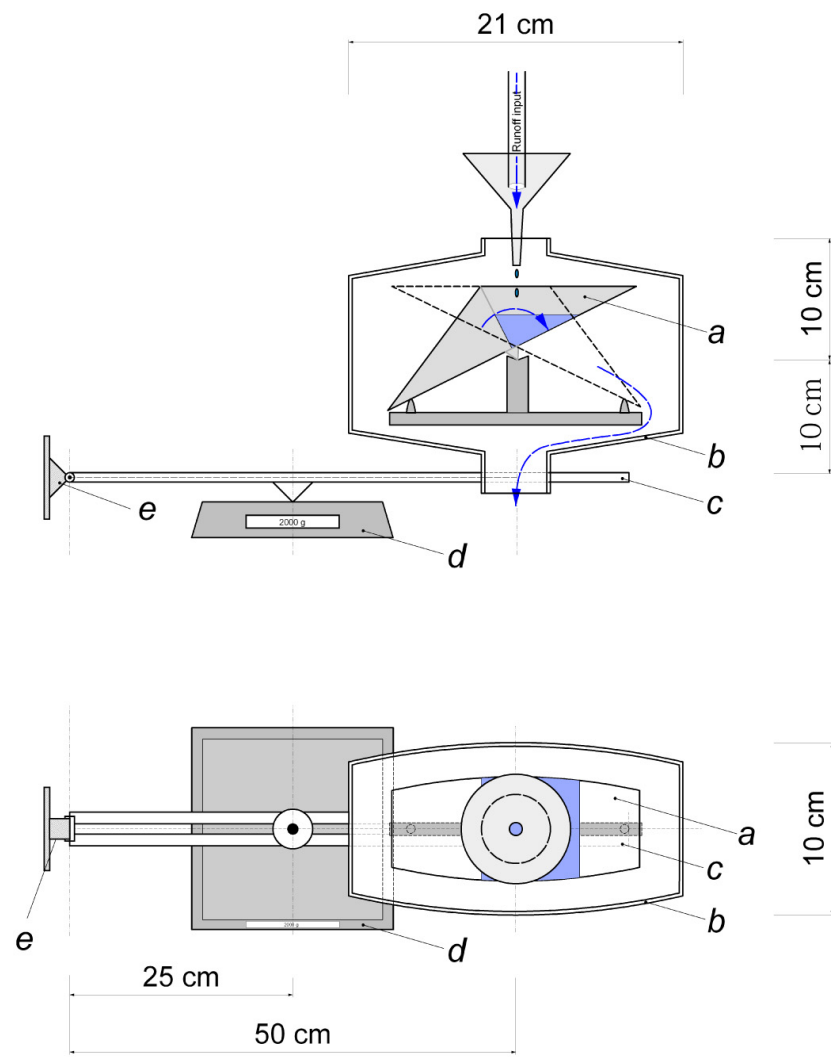

Fig. 2. Diagram of the weighable tipping bucket system. The blue arrow indicates the way the water has to go when leaving the (a) tipping bucket and (b) the box. The other parts of the set-up are (c) the lever connected to the balance by a screw, (d) the balance and (e) the pivot.

with $n$ the number of tippings, $\bar{V}_{\mathrm{B}}$ the bucket volume [1] and $A\left[\mathrm{~m}^{2}\right]$ the paved surface area.

The WTB data is processed as follows: the volume of water collected before the first tipping $\left(V_{\mathrm{FT}}\right)$ is calculated as difference between the volume before the beginning of runoff and the highest volume detected. The volume of water collected after the last tipping of an event $\left(V_{\mathrm{LT}}\right)$ is calculated as the difference between the lowest volume of the tipping bucket and the volume at the end of the event.

The beginning of the event is identified as follows: if the subsequent run-off has completely finished, it is the first positive mass change detected by the balance after a long period of no changes or decreasing water volumes due to evaporation. If the subsequent rain event is over, but the run-off is still collected, the two rain events and the according run-off events cannot be separated and are processed as one event.

When the rain is over and the run-off from the surface also stopped, the WTB can still collect water. Such water is rather the draining of the gutter system than run-off. In general, the end of the run-off from an investigated surface might be different from the time when the last drop entered 
the WTB. In our case, artifacts are caused by the metal gutter and the $1.5 \mathrm{~m}$ metal pipe leading the water to the WTB in the lysimeter basement. We observed the run-off from the surface stopping after about $10 \mathrm{~min}$, but the last drop entering the WTB after $30 \mathrm{~min}$. This delay is due to the water which wet the gutter is slowly running out of the pipe after surface run-off stopped, leading to a very long tailing of the run-off curve (Fig. 3). To retrospectively identify the end of the surface run-off from the WTB data, we used the time, when the flow rate was less than $0.0021 \mathrm{~min}^{-1}$. This criterion is conceived based on our observations in our individual gutter system and is therefore applicable only for our experiments. Other criterions are possible, such as the time when $95 \%$ of run-off entered the WTB. However, water with a flow rate $<0.0021 \mathrm{~min}^{-1}$ is still accounted to the sum of run-off, but does no longer count in terms of run-off duration.

After the first tipping every tipping is accounted with $\bar{V}_{\mathrm{B}}$ [1]. The sum of the run-off event measured by the WTB $\mathrm{RO}_{\text {WTB }}$ is therefore:

$\mathrm{RO}_{\mathrm{WTB}}=\left\{\begin{array}{l}\frac{V_{\mathrm{FT}}}{A} \text { for } n=0 \\ \frac{(n-1) \bar{V}_{\mathrm{B}}+V_{\mathrm{FT}}+V_{\mathrm{LT}}}{A} \text { for } n \geq 1, n \in \mathbb{N}\end{array} \quad[\mathrm{mm}]\right.$

with $V_{\mathrm{FT}}$ [1] the volume of water collected before the first tipping and $V_{\mathrm{LT}}$ [1] the volume of water collected after the last tipping of an event.

The run-off sum for the observation period was calculated as the sum of the individual events both for TB and WTB data according to Eqs. 1 and 2. The surface storage $V_{\mathrm{S}}$ was estimated by the maximum rain event sum, at which no runoff was detected, both using TB and WTB data.

\section{Results and discussion}

\subsection{Increased volume resolution of surface run-off measurements using the WTB}

The run-off generation from the permeably paved lysimeter surface has been studied using and comparing the data gained from the TB and the WTB. Exemplary, one single run-off event at the 3 September 2009 is shown in Fig. 3 and discussed in the following. The rain event started at 10:42 lasted for $33 \mathrm{~min}$ and had a sum of $1.2 \mathrm{~mm}$. For the current $\mathrm{RO}$ event, the TB tipped five times and a run-off of $0.5 \mathrm{~mm}$ and $0.45 \mathrm{~mm}$ was detected by the TB and the WTB respectively. Note that from 10:43 until 11:03 the amount of 0.0041 entered the WTB. This water has been left in the gutter system from the subsequent rain event which ended 9:45 and was also accounted to the subsequent $\mathrm{RO}$ event.

The absolute difference $\mathrm{RO}_{\mathrm{WTB}}-\mathrm{RO}_{\mathrm{TB}}$ is $-0.05 \mathrm{~mm}$. The relative difference $U$ (Eq. 3 ) is $-10 \%$, while the maximum difference would be $-17 \%$ (see Eq. 4).

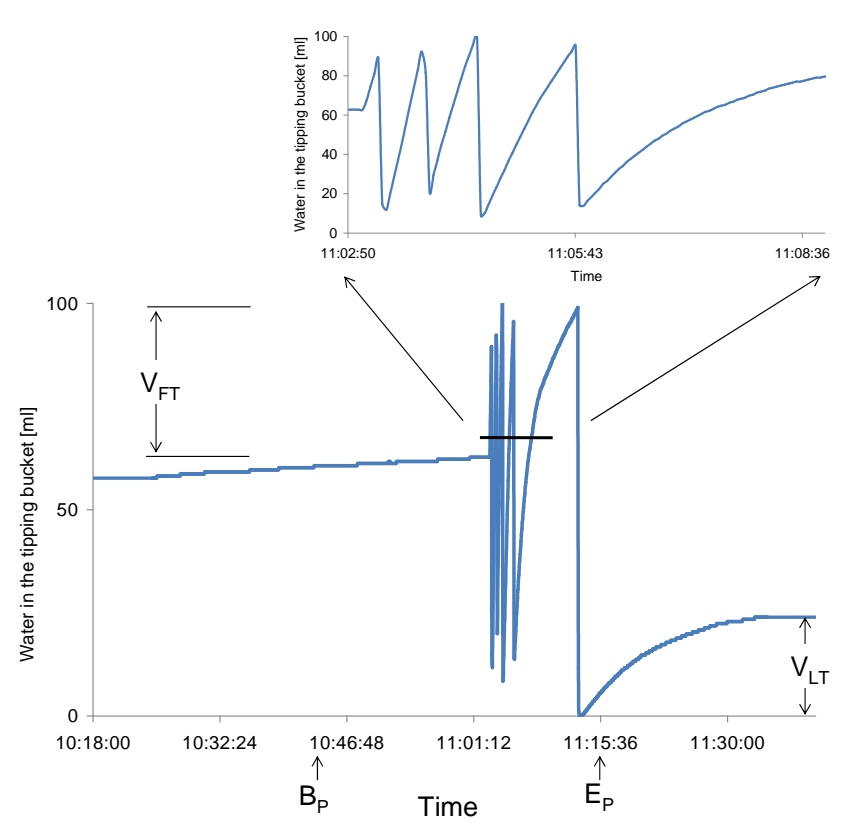

Fig. 3. Run-off event from concrete pavement at the 3 September 2009 in Berlin-Marienfelde, Germany. The run-off event was studied using the weighable tipping bucket. Indicated are the filled bucket volumes at the beginning $\left(V_{\mathrm{FT}}\right)$ and at the end of the run-off event $\left(V_{\mathrm{LT}}\right)$ as well as the beginning $\left(B_{\mathrm{P}}\right)$ and the end $\left(E_{\mathrm{P}}\right)$ of the precipitation event.

That underlines the great advantage of the WTB system and gives an impression of the reliability of measurements with solely the TB.

In Fig. 3 the water volumes for the maximum filled and the empty buckets vary. This might be due to differing volumes for the left and the right buckets, as this has been estimated during calibration of the system. While the left bucket volume is 0.10291 , the right bucket only fills up to 0.09551 until tipping, resulting in a $\bar{V}_{\mathrm{B}}$ of 0.09871 . However, this effect is not the only reason, as the volumes of water at tippings are not reproducible.

Furthermore, other effects are responsible: (i) water needs some time to flow out of the TB box, which is indicated in Fig. 2. In the mean time, water enters the TB box from above. Thus, the WTB detects water, entering and leaving the TB box in the same time step. The resulting uncertainty is proportional to the flow intensity. Consequently, the balance detected the lowest weight for the empty bucket and one of the highest weights for the full bucket, when the flow intensity was the smallest at the end of the run-off event shown in Figs. 3 and 4.

The different maximum and minimum bucket weights are also (ii) an artifact of the $3 \mathrm{~s}$ measuring interval of the balance. For the run-off event at the 3 September 2009 mentioned above we calculated a flow rate of $3.3 \times 10^{-3} 1 \mathrm{~s}^{-1}$ for the interval between the first and the second tipping of the 


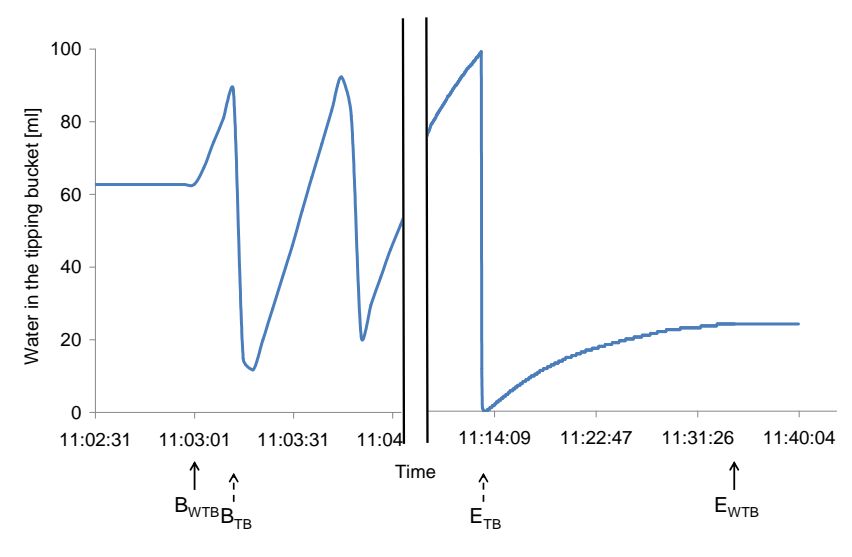

Fig. 4. Run-off event from concrete pavers at the 3rd of September 2009 in Berlin-Marienfelde. The dynamics were studied using the traditional tipping bucket (TB) signals compared to the weighable tipping bucket (WTB) data. $B_{\mathrm{TB}}, B_{\mathrm{WTB}}$ and $E_{\mathrm{TB}} E_{\mathrm{WTB}}$ indicate the beginning and the end of the run-off event as detected by the tipping bucket and the weighable tipping bucket, respectively. Note, that the time axis is interrupted and scaled differently.

TB. That results in an uncertainty of $\approx 0.011$ for the maximum and minimum filling of the TB at this flow rate and the given temporal resolution of the digital balance.

Because of (i) and (ii), the run-off is calculated from the tipping signals instead of the balance data between the first and the last tipping of the bucket (see Eq. 2).

Furthermore, (iii) the buckets of the TB spin along the leverage and not perpendicular to it. For technical reasons in our individual case, it was not possible to mount the tipping bucket in a different way. That means, similarly filled buckets would lead to different weights detected by the balance due to the different torques. The two buckets have the leverage factors: 0.50 for the shorter lever and 0.52 for the longer lever. However the bucket volumes were calculated using the average factor of 0.51 for the first approximation.

\subsection{Systematic uncertainty of TB compared to WTB}

While the discrepancy between run-off measurement by TB and WTB can be high for a single event, it will be smaller after a long observation period with a high number of tippings as then, the relative contribution of the first and the last tipping to the sum of tippings decreases.

In the following, the maximum relative difference between WTB and TB $\left(U_{\max }\right)$ for a certain number of TB-tippings is calculated. We consider the WTB data to be more precise than the TB data for the following reasons: The WTB system uses the same tipping information as the TB but also delivers information about the water flow in periods between two tippings. In this periods the WTB has the 100 times higher volume resolution compared to the TB. A testing of the assumption of the higher precision of the WTB in a physical experiment is hardly possible. First, the device is compared to exactly itself. Any test of the weighing function of the WTB must be based on the quantification of a water flow which would only be possible with another balance, as mass and time are the basic physical measurements. In such a test one balance signal would just be compared to another balance signal.

The relative detection limit of the digital balance compared to the bucket $(x)$ can be expressed as $x=V_{\min } / \bar{V}_{\mathrm{B}}$. With $V_{\min }=0.0011$ and $\bar{V}_{\mathrm{B}}=0.11 x$ equals 0.01 .

Generally, $\mathrm{RO}_{\mathrm{WTB}}$ can be higher or lower than $\mathrm{RO}_{\mathrm{TB}}$ leading to positive or negative differences. In case of the maximum positive difference $\mathrm{RO}_{\mathrm{WTB}}-\mathrm{RO}_{\mathrm{TB}}$ the bucket is almost empty $(=0.001 \mathrm{l})$ at the beginning of the event and is left almost filled $(=0.0991)$ at the end (then, $U_{\max } \rightarrow \max$ for $\left.\left(V_{\mathrm{FT}}+V_{\mathrm{LT}}\right) \rightarrow 2\left(V_{\mathrm{B}}-x V_{\mathrm{B}}\right)\right)$. In case of the maximum negative difference, the bucket is almost full at the beginning of the event $(=0.099 \mathrm{l})$ but left almost empty $(=0.001 \mathrm{l})$ at the end (then, $U_{\max } \rightarrow \min$ for $\left.\left(V_{\mathrm{FT}}+V_{\mathrm{LT}}\right) \rightarrow 2 x V_{\mathrm{B}}\right)$.

Substituting

$U_{\max }=\frac{\mathrm{RO}_{\mathrm{WTB}}-\mathrm{RO}_{\mathrm{TB}}}{\mathrm{RO}_{\mathrm{WTB}}} \times 100 \%$

with Eqs. (1) and (2) for $V_{\mathrm{FT}}+V_{\mathrm{LT}} \rightarrow 2 x V_{\mathrm{B}}$ and $V_{\mathrm{FT}}+$ $V_{\mathrm{LT}} \rightarrow 2\left(V_{\mathrm{B}}-x V_{\mathrm{B}}\right)$ reveals:

$\frac{-1+2 x}{n-1+2 x} \times 100 \% \leq U_{\max } \leq \frac{1-2 x}{n+1-2 x} \times 100 \%$

From Eq. 4 one can learn that the maximum systematic uncertainty is highest for small run-off volumes leading to no or only a small number of tippings. $\left|U_{\max }\right|$ is lower than $5 \%$ and $1 \%$ for 21 and 99 tippings which equals a run off of $2.1 \mathrm{~mm}$ and $9.8 \mathrm{~mm}$. The rain distribution in Fig. 1 demonstrates that uncertainties higher than $5 \%$ must be assumed at least for $28 \%$ of all rain events (assuming a linear RC of 1) when a TB is used for measurements. However, we know that $\mathrm{RC}$ is not linear for different rain intensities and that due to evaporation of rain water from the surface and infiltration higher maximum systematic uncertainties must be assumed for the quantiles mentioned above.

\subsection{Increased temporal resolution of run-off measurements using the WTB}

Employing WTBs instead of TB increases the temporal resolution of the run-off observation. The rain event at 3 September 2009 started at 10:42 a.m., lasted for $33 \mathrm{~min}$ and had a sum of $1.2 \mathrm{~mm}$ (Fig. 3). The according run-off event lasted from 11:03:01 a.m. until 11:33 a.m. as detected by the WTB, but only from 11:03:13 a.m. until 11:13 a.m. as detected by the TB (Fig. 4).

Although depending on the water level in the bucket, the starting times of run-off events detected by TB and WTB might be close. This is due to the steep increase of the runoff intensity at the beginning of the event. At the end of the 
run-off event, the flow intensity tails out slowly. From the TB data, the run-off already stopped before the end of the rain. That is not impossible. It could be explained by processes like evaporation or infiltration. The low volume resolution of the system leads to a very low temporal resolution. In contrast, the WTB can detect the end of the run-off event much better due to its increased volume resolution and the constant high temporal resolution.

That has important consequences for the measurement of run-off dynamics, e.g. the run-off concentration time $\left(t_{\mathrm{c}}\right)$. Measuring with the TB, for a given rain intensity and a given moisture content in the pavement, $t_{\mathrm{c}}$ depends on pavement characteristics such as $V_{\mathrm{S}}$, rain intensity and other climatic conditions but also on the level of water in the bucket, left from the last event. Measuring with the WTB in contrast, detects a $t_{\mathrm{c}}$ which is almost only depending on pavement, rain intensity and the climatic characteristics.

\subsection{Run-off sum for the five months period}

During the observation period 8 July until 1 December 2009, the TB detected a total of $71.6 \mathrm{~mm}$ while the WTB detected $79.6 \mathrm{~mm}$. The difference is equal to $11 \%$ of the total run-off detected by the TB. Up to $95 \%$ of the difference can be explained by evaporation losses from the TB. During the measurement period, a quantity of 7.61 evaporated from the TB, as calculated from weight losses of the WTB in periods between run-off events.

In this study, not the sum of run-off after a long period but the individual run-off events were of interest, especially those caused by small rain events. In the observation period, the rain-gauge detected 154 rainfall events, leading to 121 and 47 run-off events detected by the WTB and TB respectively. The higher resolution of the WTB compared to the TB leads to more observations and will lead to a different description of run-off processes.

This is shown by the following example: Although the RC is not constant for different precipitation events one can calculate an average run-off coefficient $(R C)$ and its standard deviation (SD) for the detected $\mathrm{RO}$ events, just in order to compare the data sets: $\overline{R C}$ TB is $0.38(\mathrm{SD}=0.21, \mathrm{~N}=47)$ while $\overline{R C}$ WTB is only $0.10(\mathrm{SD}=0.23, \mathrm{~N}=121)$ for events detected by the WTB. Using TB-data would overestimate the run-off formation compared to WTB-data. Additionally, WTB-data has higher variation than TB-data, thus the first delivers more comprehensive information for process studies than the latter.

\subsection{Estimation of initial loss for paved surfaces from run-off measurements}

As not all rain events lead to run-off, there must be a retainment of water on or in the pavers. It is not the goal of this paper to study this topic in detail, but we can show that the magnitude of $V_{\mathrm{S}}$ strongly depends on the volume resolution of the measuring device.

According to our hypothesis, the storage $V_{S}$ is the sum of free water retained at the surface of pavers in its micro relief $\left(V_{\mathrm{R}}\right)$, the air filled pore volume of porous pavers $\left(V_{\mathrm{P}}\right)$ and the air filled pore volume of the seam material and the underlying soil $V_{\mathrm{SM}}$.

$V_{\mathrm{S}}=V_{\mathrm{R}}+V_{\mathrm{P}}+V_{\mathrm{SM}}[\mathrm{mm}]$

$V_{\mathrm{S}}$ is a function of the initial water content and a material and design characteristic of the pavers and the pavement system as well as a function of the pore system properties of seam material and the underlying soil. First estimations of the maximum $V_{\mathrm{Smax}}$ can be derived from the maximum rain events which did not lead to run-off. Analyzing the TB data, $V_{\text {Smax }}$ is then $2.5 \mathrm{~mm}$ but only $1.7 \mathrm{~mm}$ using WTB data. So the lower volume resolution of the TB would lead to an overestimation of the initial loss of $47 \%$. That would in turn lead to a underestimation of run-off in process based models, which consider such initial loss.

\section{Conclusions}

The analysis of run-off events detected by traditional tipping buckets can be substantially improved by the information about water levels in the tipping buckets between two tippings by weighing the whole TB system. Additionally, the volume and the temporal resolution of a traditional TB are enhanced, which decreases the systematic uncertainty of the measurements. This enables us to very precisely describe the flow dynamics and to synchronize flow measurements to the constantly timed measurements of other water balance components e.g. in high resolution lysimeter studies.

The already existing TB system was not substituted but enhanced. That offers excellent potential to upgrade existing TB systems in order to improve their volume detection limit and their temporal resolution. So, it is also possible to retrospectively calibrate already installed tipping buckets, that means to quantify their uncertainty. The balance also offers the option to monitor the performance of the tipping counter. This applies for run-off studies for both paved and open soil surfaces but also for seepage detection in lysimeters and wick samplers respectively for all flow measurements.

Acknowledgements. This study was funded both by the DFG GRK 780/III and the Technische Universitaet Berlin, Department of Ecology, Chair of Soil Conservation. We gratefully thank the Umweltbundesamt (Federal Environment Agency of Germany), personally Dr. Norbert Litz for the organizational support for our lysimeters. We thank our colleagues Steffen Trinks, Michael Facklam and Bjoern Kluge for their help installing the lysimeters and Andre Peters for the discussions.

Edited by: A. Shamseldin 


\section{References}

Arnbjerg-Nielsen, K.: Significant climate change of extreme rainfall in Denmark, Water Sci. Technol., 54, 1-8, 2006.

Arnbjerg-Nielsen, K. and Fleischer, H. S.: Feasible adaptation strategies for increased risk of flooding in cities due to climate change, Water Sci. Technol., 60, 273-281, 2009.

Arnbjerg-Nielsen, K. and Harremoes, P.: Prediction of hydrological reduction factor and initial loss in urban surface runoff from small ungauged catchments, Atmos. Res., 42, 137-147, 1996.

Edwards, I. J., Jackson, W. D., and Fleming, P. M.: Tipping Bucket Gauges for Measuring Run-Off from Experimental Plots, Agr. Meteorol., 13, 189-201, 1974.

Faram, M. G., Ashley, R. M., Chatfield, P. R., and Andoh, R. Y. G.: Appropriate drainage systems for a changing climate, P. I. Civil Eng.-Engineering Sustainability, 163, 107-116, 2010.

Gobel, P., Dierkes, C., and Coldewey, W. G.: Cooling effect of water-holding pavements made of new materials on water and heat budgets in urban areas, J. Contam. Hydrol., 91, 26-42, 2007a.

Gobel, P., Dierkes, C., Kories, H., Messer, J., Meissner, E., and Coldewey, W. G.: Impacts of green roofs and rain water use on the water balance and groundwater levels in urban areas, Grundwasser, 12, 189-200, 2007b.

Habib, E., Krajewski, W. F., and Kruger, A.: Sampling errors of tipping-bucket rain gauge measurements, J. Hydrol. Eng., 6, 159-166, 2001

Hino, M., Odaka, Y., Nadaoka, K., and Sato, A.: Effect of initial soil moisture content on the vertical infiltration - a guide to the Problem of runoff-ratio and loss, J. Hydrol., 102, 267-284, 1988.

Khan, A. A. H. and Ong, C. K.: Design and calibration of tipping bucket system for field runoff and sediment quantification, J. Soil Water Conserv., 52, 437-443, 1997.

Mansell, M. and Rollet, F.: The effect of surface texture on evaporation, infiltration and storage properties of paved surfaces, Water Sci. Technol., 60, 71-76, 2009.

Meissner, R., Rupp, H., Seeger, J., Ollesch, G., and Gee, G. W.: A comparison of water flux measurements: passive wick-samplers versus drainage lysimeters, Eur. J. Soil Sci., 61, 609-621, 2010.

Nakayama, T. and Fujita, T.: Cooling effect of water-holding pavements made of new materials on water and heat budgets in urban areas, Landscape Urban Plan., 96, 57-67, 2010.

Nehls, T., Jozefaciuk, G., Sokolowska, Z., Hajnos, M., and Wessolek, G.: Pore-system characteristics of pavement seam materials of urban sites, J. Plant Nutr. Soil Sci., 169, 16-24, 2006.
Nehls, T., Jozefaciuk, G., Sokolowska, Z., Hajnos, M., and Wessolek, G.: Filter properties of seam material from paved urban soils, Hydrol. Earth Syst. Sci., 12, 691-702, doi:10.5194/hess12-691-2008, 2008.

Pillsbury, A. F., Osborn, J. F., Pelishek, R. E., and Szuszkie, Te.: Effects of Vegetation Manipulation on Disposition of Precipitation on Chaparral-Covered Watersheds, J. Geophys. Res., 67, 695699, 1962.

Ragab, R., Rosier, P., Dixon, A., Bromley, J., and Cooper, J. D.: Experimental study of water fluxes in a residential area: 2 . Road infiltration, runoff and evaporation, Hydrol. Process., 17, 24232437, 2003.

Rim, Y.-N.: Untersuchungen zum Abflussverhalten unterschiedlicher Flaechenbefestigungen in Lysimetern, Department of soil conservation, Technische Universitaet Berlin, 2008.

Rim, Y.-N., Wessolek, G., Trinks, S., and Nehls, T.: Eine waegbare teilversiegelte Lysimeteranlage in Berlin. 13. Gumpensteiner Lysimetertagung 2009, Lehr- und Forschungszentrum fr Landwirtschaft, Raumberg-Gumpenstein, Gumpenstein, Austria, 2009.

Sen, Z. and Altunkaynak, A.: A comparative fuzzy logic approach to runoff coefficient and runoff estimation, Hydrol. Process., 20, 1993-2009, 2006.

Senatsverwaltung fuer Stadtentwicklung Berlin: Umweltatlas Berlin. Senatsverwaltung fuer Stadtentwicklung und Umweltschutz, Berlin, available at: http://www. stadtentwicklung.berlin.de/umwelt/umweltatlas/index.shtml, last access: 22 September 2010, 2001.

Wessolek, G. and Facklam, M.: Standorteigenschaften und Wasserhaushalt von versiegelten Flaechen, J. Plant Nutr. Soil Sci., 160, 41-46, 1997.

Wessolek, G., Duijnisveld, W. H. M., and Trinks, S.: Hydropedotransfer functions (HPTFs) for predicting annual percolation rate on a regional scale, J. Hydrol., 356, 17-27, 2008.

White, E. J. and Rhodes, P. S.: A tipping bucket recorder for use in stem flow studies, J. Appl. Ecol., 7, 349-351, 1970.

World Meteorological Organization: Guide to Meteorological Instrument and Observing Practices, World Meteorological Organization, Geneva, WMO-No. 8 TP 3, 1961.

Yu, B., Ciesiolka, C. A. A., Rose, C. W., and Coughlan, K. J.: Note on sampling errors in the rainfall and runoff data collected using tipping bucket technology, T. Asae, 40, 1305-1309, 1997. 